University of Nebraska - Lincoln

DigitalCommons@University of Nebraska - Lincoln

8-1996

\title{
A Renaissance of Political Culture?
}

Robert W. Jackman

University of California - Davis

Ross A. Miller

University of Nebraska - Lincoln, rmiller10@unl.edu

Follow this and additional works at: https://digitalcommons.unl.edu/poliscifacpub

Part of the Political Science Commons

Jackman, Robert W. and Miller, Ross A., "A Renaissance of Political Culture?" (1996). Faculty Publications: Political Science. 50.

https://digitalcommons.unl.edu/poliscifacpub/50

This Article is brought to you for free and open access by the Political Science, Department of at DigitalCommons@University of Nebraska - Lincoln. It has been accepted for inclusion in Faculty Publications: Political Science by an authorized administrator of DigitalCommons@University of Nebraska - Lincoln. 


\title{
A Renaissance of Political Culture?*
}

\author{
Robert W. Jackman, University of California, Davis \\ Ross A. Miller, Santa Clara University
}

Theory: Cultural differences drive significant elements of political and economic life.

Hypotheses: (1) effective governance hinges critically on traditions of civic engagement; (2) political culture fundamentally drives economic performance and democratic stability.

Method: Reanalysis of two data sets: (1) the first includes information collected by Putnam (1993) on a variety of political, economic and social indicators for the 20 Italian regions; (2) the second includes comparable information collected by Inglehart (1990) for the industrial democracies.

Results: We find little evidence to indicate a systematic relationship between political culture and political and economic performance.

Ever since Max Weber, many social scientists looked at the 'right' cultural attitudes and beliefs as necessary conditions ('prerequisites') for economic progress, just as earlier theories had emphasized race, climate, or the presence of natural resources. In the 1950s, newly fashioned cultural theories of development competed strongly with the economic ones (which stressed capital formation), with Weber's Protestant Ethic being modernized into David McClelland's 'achievement motivation' as a precondition of progress and into Edward C. Banfield's 'amoral familism' as an obstacle. According to my way of thinking, the very attitudes alleged to be preconditions of industrialization could be generated on the job and 'on the way,' by certain characteristics of the industrialization process. (Hirschman 1984, 99)

The belief that cultural differences underlie many of the observed variations across political units has a long pedigree, especially among students of comparative politics. The classic exemplar of the argument remains Max Weber's analysis of linkages between the Protestant Ethic and the rise of capitalism in Europe ([1905] 1958). A benchmark study of the behavioral

\footnotetext{
*We would like to thank Donna Bahry, Henry Brady, Bruce Bueno de Mesquita, Mary Jackman, Randolph Siverson, and the editor and referees for their comments, and Robert Putnam for generously providing us with access to his data on the Italian regions. We also acknowledge support from the Institute of Governmental Affairs and the Academic Senate, University of California, Davis. Documentation and information necessary to reconstruct the analysis are available from the authors.
}

American Journal of Political Science, Vol. 40, No. 3, August 1996, Pp. 632-59 (C) 1996 by the Board of Regents of the University of Wisconsin System 
revolution in the study of politics is Almond and Verba's (1963) exploration of linkages between civic cultures and democracy across five societies.

While the popularity of this general perspective has waxed and waned over the past three decades (e.g., the essays in Almond and Verba 1980; Barry 1970, especially chaps. 3,4), the presumption that cultural differences drive significant elements of political and economic life enjoys a wide currency. Two major recent studies are especially noteworthy, because they are intended as part of a "renaissance" of political culture, to use Inglehart's (1988) term. The newest, Making Democracy Work (Putnam 1993), compares regional governments in contemporary Italy and contends that effective governance hinges critically on traditions of civic engagement. In so doing, it parallels Culture Shift (Inglehart 1990), which, after examining a number of industrial societies, concludes that political culture fundamentally drives economic performance and democratic stability.

Such arguments are of more than academic interest. For example, it is often asserted that democratization will continue to face severe handicaps in the southern European cone, much of Latin America, and most strikingly in East Europe and Russia, given the strong legacy of authoritarianism in the recent past. These claims, moreover, have already received a good deal of attention. According to The Economist, for example, Putnam (1993) is "a great work of social science, worthy to rank alongside de Tocqueville, Pareto, and Weber' (The Economist 1993, 96), while Laitin judges Putnam's book to be a "stunning breakthrough in political culture research" (1995, 171).

Our purpose is to assess the broad elements of the cultural interpretation. We first outline the distinctive attributes of this explanation and then evaluate the data offered by Putnam and Inglehart in light of those same attributes. ${ }^{1}$ To what extent does the available evidence point to well-defined and enduring types of political cultures? Are there any systematic linkages between political culture and other outcomes? As will become clear, our results indicate that the cultural accounts of political life are substantially overstated. Taking these results in conjunction with other evidence, we conclude by suggesting that the political culture approach needs to be recast in institutional terms that more directly acknowledge the role of political considerations in explaining performance.

\section{The Distinctive Elements of the Political Culture Approach}

Early studies of political culture frequently offered a unique exegesis of political behavior within a given state, often cast in terms of national

\footnotetext{
${ }^{1}$ An earlier version of Putnam's analysis of the Italian material appears in Putnam, et al (1983), and a parallel analysis of the United States is summarized in Putnam (1995). We focus on the core issues Inglehart (1990) addresses in his Chapter 1 ("Culture, Stable
} 
character. The notable exception, of course, was Weber's effort to identify the peculiar characteristics of Protestantism that might account for the association he observed between the relative size of the Protestant population in various areas of Europe and the economic growth those areas experienced. Weber's answer emphasized the challenge to Medieval discipline represented by Protestantism, along with distinctive values associated with Protestantism that he believed fostered entrepreneurial skills. ${ }^{2}$

In an analogous manner, Almond and Verba (1963) sought to identify the features of political culture that foster democratic performance. They paid special attention to the contrast between participant and subject cultures, arguing that democratic outcomes are more likely where participatory norms are widespread, and less likely where values take a predominantly passive, subject form. At about the same time, McClelland (1961, 1963) suggested that high concentrations of values emphasizing need for achievement are the engine that drives economic growth. Since need for achievement is a syndrome that emphasizes entrepreneurial skills, the parallels with Weber are direct. McClelland further suggested that authoritarian regimes were the likely outcome of cultures that stressed high levels of need for power and low levels of need for affiliation. Banfield $(1958,85)$ made the similar argument that economic and political "backwardness" is a function of high levels of amoral familism according to which the norm is to "maximize the material, short-run advantage of the nuclear family; assume that all others will do likewise." Thus defined, amoral familism resembles both Almond and Verba's subject culture and McClelland's views on low levels of need for achievement. These concerns are echoed in the more recent analyses. For example, Putnam's (1993) emphasis on sense of civic community matches Almond and Verba's case for the importance of a civic political culture: "Citizens in a civic community, though not selfless saints, regard the public domain as more than a battle-ground for pursuing personal interest" (Putnam 1993, 88).

In contrast with the early national character studies that stressed the uniqueness of different political systems, then, cultures are taken to reflect

Democracy, and Economic Development'), because these are the concerns that frame and justify his subsequent analyses. He addressed the same material in Inglehart (1988).

${ }^{2}$ But religious control hardly evaporated with the Reformation, as was underscored by the theocracies associated with Calvin in Geneva and Cromwell in the Republic of the Saints. Despite Weber, doctrinal issues may indeed have been less central to the Reformation than strategic and fiscal concerns (Manchester 1993). Indeed, as De Long has pointed out, "Protestantism" is correlated with other factors like early specialization in manufacturing and a high investment ratio. Thus, for the now wealthy states of Western Europe, their religious tradition has been "a surprisingly good proxy for the social capability to assimilate modern technology” (De Long 1988, 1148). 
relatively coherent clusters of attitudes. For some analysts, the syndrome involves the prevalence of entrepreneurial sentiments (as in need for achievement), while for others it is said to reveal a sense of civic community or civic virtue (as in Banfield, Almond and Verba, Inglehart, and Putnam). The important point, however, is that the syndrome is coherent.

A second point follows immediately: arguments about political culture are fundamentally concerned with the prevalence of such value clusters within societies. While the cultural pattern reflects the attitudes of individu$a l s$, it assumes political and social significance to the extent that it is widely shared across individuals. At their heart, cultural arguments are thus concerned with aggregate properties of societies. By Weber's original account, for example, it was the widespread diffusion of entrepreneurial attitudes fostered by Protestantism that gave rise to economic growth.

Third, these cultural syndromes are durable. Even if slightly modified by short-term forces, their fundamental effects persist over the long haul. Such was clearly the pattern described by Weber, and Putnam (1993) traces the recent success of Italian regional governments to legacies of civic engagement reaching back to the Middle Ages. The point is also stressed in Inglehart's $(1990,422)$ suggestion that "People live in the past much more than they realize." In other words, the impact of direct experience on behavior is severely constrained by norms passed across generations through early socialization (see also, Verba 1965, 554; Moore 1966, 485). Cultural factors thus condition how individuals adapt to changes in incentive structures embodied in institutions, which distinguishes the perspective from social choice arguments, as Inglehart and others have pointed out. ${ }^{3}$

Fourth, the significance of these enduring cultural syndromes stems from the way in which they drive other outcomes. Thus, Weber's analysis continues to attract attention because of the effects on economic growth he attributed to Protestantism, and it is hard to imagine this continuing attention without that imputation. Weber was, of course, quite explicit on the point. His fundamental goal was to undermine any form of "economic determinism" by showing that values are not epiphenomenal, Marx to the contrary (see on this point, e.g., Zeitlin 1990). Banfield (1958) was equally specific: Why was Montegrano so backward? Because amoral familism was endemic. In a parallel manner, Putnam argues against any "simple economic determinism"' $(1993,152)$, insisting instead that cultural norms as reflected in a sense of civic community are responsible for both economic and political performance (1993, 98-9; see also Inglehart 1990, chap. 8).

\footnotetext{
${ }^{3}$ This is the case even though Inglehart is incorrect when he suggests that social-choice arguments are concerned solely with the maximization of economic utility. On this point, see Riker (1990), Aldrich (1993), Jackman (1993), and Poundstone (1993, 51-2).
} 
In sum, the political culture account identifies distinctive clusters of attitudes that are widely held across individuals. These durable clusters form subjective world orientations that are highly resistant to change, and are seen as the fundamental generator of economic and political performance. ${ }^{4}$ They are, in this sense, more crucial than objective conditions embodied in institutions, and they endure in the face of institutional change.

Note the policy implications of this claim. As Moore (1966), Portes (1976) and others have noted, the argument allows for slow change at most, since it casts subjective orientations as more important than, and largely independent of, objective conditions. If regional differences in civic-mindedness across contemporary Italy date back to the Middle Ages, meaningful change in the future is unlikely. Poor economic and political performance stem from cultural pathologies that, in the words of another scholar, are "self-generating in the double sense that socialization perpetuates both the cultural patterns of the group and consequent individual psycho-social inadequacies blocking escape from [them]" (Valentine 1968, 141).

Putnam and Inglehart marshall considerable data from two distinctive but complementary settings in support of the cultural perspective. As we show below, however, this evidence is not as persuasive as it might first appear. We begin by reconsidering the evidence offered in Putnam's analysis of regional governance in Italy, and then turn our attention to Inglehart's study of differences in civic culture across the industrial democracies as a whole.

\section{Civic Virtue in Italy}

Putnam's purpose is to account for the variance in the performance of political institutions across Italy's 20 regions. These regions vary significantly in terms of wealth, social structure, and, according to Putnam, in terms of political culture. This setting is of special interest because the creation of new regional governments in the 1970s provided an opportunity to conduct what Putnam calls a "unique experiment" that assesses the effect of political culture on institutional performance. The study itself is based on an extensive data set concerning a wide variety of social, economic and political attributes of each region. While the bulk of this information refers to the contemporary period, Putnam also includes quantitative material dating back to the last part of the nineteenth century.

Putnam contends that regional variations in political culture outperform

\footnotetext{
${ }^{4}$ At various points in his concluding chapter, Putnam labels these subjective orientations as "social capital," by which he means those "features of social organization, such as trust, norms, and networks, that can improve the efficiency of society by facilitating coordinated actions"' $(1993,167)$.
} 
economic development in explaining Italian regional government performance since the 1970s. Apparent support for this conclusion comes from a regression of institutional performance on current political culture and level of economic development. The estimates we obtain (using Putnam's data) are:

$$
\begin{gathered}
\text { Performance }=0 . \underset{(5.7)}{0.00} \underset{(\mathrm{CCV})}{1.20}-\underset{(1.5)}{0.32(\mathrm{ED})} \\
R^{2}=.86, N=20
\end{gathered}
$$

where Performance is Putnam's measure of institutional performance, c. 1970, CCV and ED are his measures of current civic culture and economic development, respectively, and $t$-ratios are reported in parentheses. When data for earlier cultural traditions are substituted for current patterns, the estimates are:

$$
\begin{aligned}
& \text { Performance }=-0.04+1.16(\mathrm{ECV})-0.19(\mathrm{ED}) \\
& R^{2}=.74, N=17 \text {, }
\end{aligned}
$$

where ECV is Putnam's measure of earlier civic values from the turn of the century, and other terms are defined as in [1]. Estimates like these would seem to suggest that while the effects of earlier civic traditions are weaker than those of current civic culture, both outperform economic development in the explanation of institutional performance.

Putnam's statistical analysis of the effect of political culture on democratic governance relies primarily on the three variables just identified: institutional performance, civic community and (earlier) civic traditions. Each of these variables is a composite measure created by combining an assortment of indicators on the basis of a principal components analysis. As is well-known, this is a statistical procedure "that linearly transforms an original set of variables into a substantially smaller set of uncorrelated variables that represents most of the information in the original set of variables"' (Dunteman 1989, 7, our emphasis. See also Flury 1988).

Putnam extracts a single measure of each of the three variables mentioned above from a variety of indicators. He proceeds by specifying in advance that no more than one component be extracted at each phase of the analysis. He thus simply assumes that each of the three variables is 
unidimensional. ${ }^{5}$ The question, then, is whether the composite variables constructed by Putnam reflect most of the information contained in the composite indicators from which they are formed.

\section{Measuring Institutional Performance}

To construct his dependent variable, Putnam selects indicators based on four elements: policy process and internal operations, policy decision content, policy implementation, and bureaucratic responsiveness (1993, 66-73). In all, 33 indicators are used to reflect these different elements. Putnam defends the large number of indicators on the grounds that "no single metric, taken in isolation, would suffice to rate the regions fairly. Collectively, however, these indicators can undergird a broad-based assessment of institutional performance"' $(1993,66-7){ }^{6}$

To avoid evaluating an underidentified model (since there are 33 variables but only 20 cases), the analysis proceeds in steps. First, Putnam considers 24 of the indicators, which he breaks down into three subsets. Three factors are generated from separate component analyses on each of these subsets, with the proviso that no more than one component be extracted in each of the three analyses. Along with the remaining nine indicators, these three factors are then subjected to an additional component analysis, in which a one-component solution is again specified in advance (Putnam 1993, 75, Table 3.2). Scores from this final component analysis are used to form the composite measure of performance in all of Putnam's subsequent analyses.

Table 1 reports the estimates we obtain from two different principal components analyses. The left margin lists the variables analyzed by the four domains of performance suggested by Putnam: policy process, policy decision content, policy implementation, and bureaucratic responsiveness. The estimates displayed in the first column of the table are generated by assuming a unidimensional solution, and correspond closely to those reported by Putnam $(1993,75) .^{7}$ Specifically, eight of the 12 indicators have

${ }^{5}$ Given this prior specification, it is obvious that Putnam's component analyses cannot then be used as a test of the dimensionality of these variables. Besides, principal components can generate a unidimensional outcome even when the variables are known to form more than one dimension (Armstrong 1967).

${ }^{6}$ The meaning of a "fair" rating of the regions is unclear. If the broad range of indicators is chosen to minimize reliability problems, there is little reason to suspect such problems given the aggregated nature of the data. If, on the other hand, the collection of indicators is chosen to minimize concerns about measurement validity, the procedure is not very helpful, for the reasons we detail below.

${ }^{7}$ The components in Table 1 are extracted from a correlation matrix like that reported by Putnam $(1993,199)$. Note that this is a pairwise correlation matrix; all of the correlations are based on the full 20 cases except for those involving Legislative innovation (variable \#5), for which data are missing for five cases. We explored two other sets of estimates. First, we imputed values for the missing cases from the remaining 11 variables. Second, we re- 
Table 1. Principal Component Analyses of Indicators of the Institutional Performance of Italian Regional Governments $(N=20$; Italicized loadings $>.60)$

\begin{tabular}{lcrrrr}
\hline & & \multicolumn{4}{c}{$\begin{array}{c}\text { Four-factor solution } \\
\text { (rotated Varimax loadings) }\end{array}$} \\
\cline { 3 - 6 } Indicator & $\begin{array}{c}\text { Single-factor } \\
\text { solution }\end{array}$ & $\mathrm{I}$ & II & III & IV \\
\hline Policy process & & & & & \\
1. Cabinet stability & .67 & .32 & .77 & -.05 & .07 \\
2. Budget promptness & .57 & -.03 & .65 & .19 & .69 \\
3. Statistical services & .79 & .65 & .21 & .19 & .45 \\
Policy decision content & & & & & \\
4. Reform legislation & .87 & .74 & .42 & .12 & .22 \\
5. Legislative innovation & .87 & .72 & .28 & .16 & .44 \\
Policy implementation & & & & & \\
6. Day care centers & .86 & .92 & .26 & -.06 & .04 \\
7. Family clinics & .63 & .82 & -.02 & .05 & .00 \\
8. Industrial policy & .59 & .27 & .07 & -.10 & .91 \\
9. Agricultural spending & .47 & .41 & .41 & -.65 & -.01 \\
10. Health spending & .50 & .33 & .37 & .76 & .02 \\
11. Housing development & .83 & .80 & .22 & -.31 & .28 \\
Bureaucratic responsiveness & & & & & \\
12. Responsiveness & .61 & .15 & .85 & .06 & .17 \\
Eigenvalue & 5.95 & 5.95 & 1.61 & 1.12 & 1.03 \\
Proportion of variance & .496 & .496 & .135 & .093 & .086 \\
Cumulative prop. of variance & .496 & .496 & .631 & .724 & .810 \\
\hline
\end{tabular}

loadings greater than .60 and the extracted component reproduces half of the variance in the 12 indicators. Masked by these numbers, however, is the existence of three additional components with eigenvalues greater than 1.0 .

As the estimates in the remaining columns of the table show, Putnam's single-factor solution does not constitute a reasonable representation of most of the information contained in the 12 indicators. When we abandon the single-factor restriction in favor of the customary eigenvalue cutoff of 1.0 (Kim and Mueller 1978, 43), the figures suggest that a four-factor solu-

moved Legislative innovation from the analysis and performed principal components on the remaining 11 indicators. Apart from the obvious fact that the second procedure generates no loadings for the omitted variable, these alternative ways of handling the missing data yield very similar estimated factor loadings to those displayed in Table 1 . 
Table 2. Correlations (absolute value) among and Principal Components Analysis of Indicators of the Bureaucratic Responsiveness of Italian Regional Governments $(N=20$; Italicized loadings $>.60)$

\begin{tabular}{|c|c|c|c|c|c|c|c|c|c|}
\hline & \multicolumn{6}{|c|}{ Correlations } & \multicolumn{3}{|c|}{ Components } \\
\hline & 1. & 2. & 3. & 4. & 5. & 6. & I & II & III \\
\hline 1. Agriculture satisfaction & - & & & & & & .14 & .09 & .98 \\
\hline 2. Health satisfaction & 0.14 & - & & & & & -.93 & .03 & .01 \\
\hline 3. Vocational satisfaction & 0.08 & 0.15 & - & & & & -.05 & -.92 & -.08 \\
\hline 4. Agriculture letter reply & 0.64 & 0.34 & 0.16 & - & & & .02 & .12 & -.81 \\
\hline 5. Health letter reply & 0.04 & 0.76 & 0.14 & 0.42 & - & & .95 & .01 & .02 \\
\hline 6. Vocational letter reply & 0.08 & 0.03 & 0.71 & 0.33 & 0.05 & - & -.09 & .93 & -.06 \\
\hline
\end{tabular}

tion is optimal. ${ }^{8}$ Jointly, these four components reproduce over $80 \%$ of the variance in the 12 indicators, a clear improvement in fit. ${ }^{9}$

A less obvious issue obscured in Table 1 concerns the use of composites generated by an initial principal components analysis as indicators in subsequent component analyses. Take the case of bureaucratic responsiveness, the last of the 12 indicators in Table 1, which was itself formed from a prior component analysis of six indicators. The first panel of Table 2 displays the correlations among these six indicators. These correlations point to three distinct clusters: agricultural satisfaction/agricultural letter reply; health satisfaction/health letter reply; and vocational satisfaction/ vocational letter reply.

A principal components analysis of the same six measures is reported in the second panel of Table 2. These estimates identify the same three distinct components that were suggested by the simple correlations. Each of these three components reflects, moreover, a distinctive policy area (agriculture, health, and vocation, respectively) and each is therefore readily understood. To force a single-component solution, as does Putnam, is to generate an uninterpretable composite. The problem is simply compounded

\footnotetext{
${ }^{8}$ The factor loadings shown in Table 1 from the four-factor estimates are from a varimax rotation. Estimates from oblique rotations are very similar, suggesting that the four factors are reasonably treated as orthogonal.

${ }^{9}$ While the first factor remains the largest, only half of the indicators load unambiguously on it. Furthermore, the four factors are not clearly interpretable. In particular, they do not correspond with Putnam's original four-fold classification of the 12 items (policy process, policy decision content, policy implementation, and bureaucratic responsiveness). The estimates in Table 1 thus show that the 12 indicators cannot be used to generate a coherent, unidimensional measure of institutional performance.
} 
when that composite is subsequently combined with 11 other indicators to form one overall summary measure of "institutional performance.", ${ }_{10}$

\section{Measuring Civic Culture}

Applying parallel analyses to the four indicators of current civic community (preference voting, referendum turnout, newspaper readership, and the frequency of sports and cultural associations), we find a pattern more consistent with Putnam's argument. Specifically, our estimates of an unrestricted principal component model show that the first component has an eigenvalue much greater than the cutoff of 1.0 , and reproduces $85 \%$ of the variance in the four indicators. In contrast, the second factor has an eigenvalue of only .28. Although the figures are a little less clear-cut, a onefactor solution also fits reasonably well with the five indicators of early civic traditions: strength of mass parties, incidence of cooperatives, membership in mutual aid societies, electoral turnout, and the longevity of local associations. Our estimates of an unrestricted model indicate that the first factor reproduces $74 \%$ of the variance in the five indicators, while the eigenvalue for the second factor is .78 .

In themselves, of course, the above patterns do not imply that the two components extracted reflect either current civic community or earlier civic traditions. ${ }^{11}$ Such questions of interpretability aside, these patterns do indi-

${ }^{10} \mathrm{~A}$ similar problem occurs with the construction of the component "housing and urban development." Within this composite we identified two distinct but correlated factors ( $r=$ .41). Using oblique rotation, the factors and their loadings are:

$\underline{\text { Variable }}$

1. Subsidized spending capacity, 1987

2. Facilitated spending capacity, 1987

3. Subsidized spending capacity, 1981

4. Housing spending capacity (A), 1985

5. Housing spending capacity (B), 1985

6. Urban development spending capacity, 1979

$\begin{array}{rrr}\text { Factor } 1 & \text { Factor } 2 \\ .06 & & .94 \\ -.92 & -.08 \\ -.38 & .67 \\ -.10 & .86 \\ -.92 & -.07 \\ -.38 & .73\end{array}$

See Putnam (1993, 72-3) for a discussion of the measures of housing and urban development.

${ }^{11}$ For example, while both measures include voter turnout as components, the connection between turnout and civic culture is quite unclear. Other studies have shown that voter turnout in general is more a function of institutional than cultural differences (Powell 1986; Jackman 1987; Jackman and Miller 1995), and there is no a priori reason to believe that turnout in Italy (either in elections during the earlier period or in referenda during the later period) should be different. Indeed, there is evidence from Putnam's data that turnout in Italian referenda during the 1970s and 1980s varied with the number of propositions to be decided, consistent with an institutional voter fatigue hypothesis (Jackman and Miller 1995, 482-3). Specifically, a pooled analysis of the five referenda from 1974 to 1987 across all 20 regions yields a regression coefficient of -2.7 for the number of items per referendum, suggesting that turnout dropped by just under $3 \%$ for each proposition added to a referendum 
cate that there is at least a statistical rationale for the single-component solution employed by Putnam in the construction of his explanatory variables. The empirical difficulty with Putnam's analysis thus appears to hinge on his dependent variable.

\section{Reassessing the Link Between Culture and Performance}

We now turn from the internal structure of Putnam's measures to consider the linkages between them. As indicated above, Putnam reports strong relationships between his composite of institutional performance and his composites of political culture (both current civic values and early civic traditions). If these estimates are robust, we should obtain similar relationships between civic culture and institutional performance when we focus on the constituent parts of each. If, however, the composite measures lack coherence, such a disaggregation will generate a much more mixed set of estimates. ${ }^{12}$ To gauge the sensitivity of the estimates to the particular indicators chosen, we regress each individual indicator of institutional performance on current civic values and early civic culture, controlling for economic development. Table 3 summarizes the regression results by reporting the estimated $t$-ratios (absolute values).

The first row of Table 3 shows the $t$-ratios from the regressions of the composite measure of institutional performance on the composite measures of current civic community and early civic traditions, respectively, controlling for economic development (these $t$-ratios correspond to those reported in Equations [1] and [2] above)..$^{13}$ The $t$-ratios for civic community and civic traditions in this top row are quite large (5.7 and 2.9, respectively), while those for economic development are much smaller (less than 2.0). Calculations like these form the basis for Putnam's conclusions, as we noted earlier.

A considerably more mixed picture emerges from the $t$-ratios for the individual components of institutional performance displayed in successive

(information on the number of propositions is from Butler and Ranney 1994, Appendix A, and the maximum proposition/referendum ratio was 5 in the period).

${ }^{12}$ Our analyses follow the logic of construct validation (e.g., Zeller and Carmines 1980). Thus, we are concerned with evaluating (a) the coherence of the composite measures of cultural values and institutional performance taken separately and (b) the linkages between the indicators of cultural values and the indicators of institutional performance.

${ }^{13} \mathrm{We}$ report the absolute value of the $t$-ratios simply to summarize the various regression analyses. With 17 degrees of freedom, a $t$-ratio of 2.11 or greater is significant at or beyond the .05 level, and a $t$-ratio of 1.74 is significant at or beyond the .10 level. Following convention, we use 2.0 as an approximate cutoff point for statistical significance. As will become clear in Table 3, the majority of the estimated coefficients have $t$-ratios considerably less than 2.0, which means that the signs of most of the regression coefficients and related estimates not reported in the tables are quite unreliable. 
Table 3. $T$-ratios from Regressions of Institutional Performance and its Components on Civic Values and Economic Development (Italian Regional Data, $N=20$ )

\begin{tabular}{|c|c|c|c|c|}
\hline \multirow[b]{2}{*}{ Dependent Variable } & \multicolumn{2}{|c|}{ Current culture* } & \multicolumn{2}{|c|}{ Early culture** } \\
\hline & $\mathrm{CCV}$ & ED & $\mathrm{ECV}$ & ED \\
\hline Overall Institutional Performance & 5.7 & 1.5 & 2.9 & 0.5 \\
\hline \multicolumn{5}{|l|}{ Policy Process } \\
\hline Cabinet stability & 3.2 & 1.9 & 1.5 & 0.8 \\
\hline Budget promptness & 1.2 & 0.0 & 0.7 & 1.3 \\
\hline Statistical services & 1.2 & 1.3 & 1.4 & 0.7 \\
\hline \multicolumn{5}{|l|}{ Policy Decision Content } \\
\hline Reform legislation & 2.4 & 0.0 & 2.8 & 0.7 \\
\hline Legislative innovation & 0.9 & 0.6 & 1.6 & 0.3 \\
\hline \multicolumn{5}{|l|}{ Policy Implementation } \\
\hline Day care centers & 2.6 & 0.7 & 4.0 & 1.5 \\
\hline Family clinics & 1.4 & 0.5 & 1.4 & 0.4 \\
\hline Industrial policy & 1.9 & 0.7 & 0.8 & 1.7 \\
\hline Agricultural spending & 0.4 & 0.7 & 0.1 & 1.0 \\
\hline Local health spending & 3.0 & 1.7 & 2.3 & 1.3 \\
\hline Housing development & 2.5 & 0.8 & 1.9 & 0.2 \\
\hline \multicolumn{5}{|l|}{ Bureaucratic Responsiveness } \\
\hline Responsiveness & 2.7 & 1.7 & 3.8 & 3.1 \\
\hline
\end{tabular}

* Absolute $t$-ratios from regressions on current civic values (CCV) and current economic development (ED).

** Absolute $t$-ratios from regressions on early civic values (ECV) and current economic development (ED).

rows of Table 3. Of the 12 regressions in the first part of the table for current culture (with economic development controlled), only six have $t$ ratios for civic community exceeding 2.0. Two of these significant $t$-ratios, moreover, are for "housing development" and "bureaucratic responsiveness," both of which are composite measures that are difficult to interpret for the reasons we have already given. The results for the corresponding regressions in the second part of the table involving early cultural traditions are even less encouraging. Of these 12 regressions, only four (or one-third) have $t$-ratios greater than 2.0.

The robustness of Putnam's conclusions is further obscured when we substitute the component indicators of culture (referenda turnout, preference voting, news associations, and sports associations) for the overall composites employed as explanatory variables in Table 3 (results not displayed). With the composite measure of institutional performance as the 
dependent variable, the results are relatively consistent, with three of the four $t$-ratios for the components of civic community in the top row larger than 2.0. This apparent consistency fades, however, when we substitute the 12 separate components of institutional performance for the composite dependent variable.

Of the distinct indicators of civic culture, referenda turnout has the most consistent effects on the different components of institutional performance, but even here, only seven of 12 estimated coefficients (58\%) have $t$-ratios of at least 2.0. For the preference voting coefficients, the number of $t$-ratios greater than or equal to 2.0 drops to five of $12(42 \%)$. Only two of the 12 coefficients $(17 \%)$ for sports associations are significant, and none of the newspaper-readership coefficients meet conventional levels of statistical significance. Indeed, of the 48 possible estimates, only 14 (or less than $30 \%$ ) have statistically significant coefficients on an indicator of civic community, and five of these are for housing development or bureaucratic responsiveness, measures whose meaning is ambiguous, as we argued earlier. That so few of the coefficients for associations and newspaper readership reflect a systematic effect is of particular interest given the centrality of association membership and the mass media in most accounts of civic vitality; indeed, Putnam approvingly quotes de Tocqueville on the point (1993, 92).

This extreme sensitivity of the estimated coefficients for culture to the particular component indicators under consideration undermines the cultural argument. The only civic community indicator that systematically affects institutional performance in at least a majority of the tests (seven of 12 ) is referenda turnout. Whether this has any implications for a political culture interpretation is unclear, for the reasons advanced earlier.

The case for a cultural explanation is even weaker when the composite measure of early cultural traditions is decomposed into its five constituent parts. Again, we do not display the estimates here, but the effects are minimal even if we restrict our attention to Putnam's overall measure of institutional performance. None of the five separate elements of early civic traditions (the strength of mass-based parties, the incidence of cooperatives, membership in mutual-aid societies, electoral turnout, and the incidence of local associations) has a $t$-ratio of at least 2.0 (although two of them are very close at 1.9 ). The estimates are still more erratic when the dependent variable is further disaggregated.

In all, we find very little indication from the Italian data to suggest that institutional performance depends in any appreciable manner on cultural traditions. While there is a statistical justification for the measures of civic community developed by Putnam, those measures do not address distributions of cultural values directly. More troubling is the fact that the measure 
of institutional performance cannot be justified even on statistical grounds. As a result, these data provide no warrant for linking cultural values to political performance.

\section{Civic Virtue in the Industrial Democracies}

We now turn to a different setting for a further empirical evaluation of the cultural argument. This centers on the analyses reported by Inglehart (1990), who examines broader cross-national variations across the industrial democracies, and whose analyses focus on different forms of performance. In addition, Inglehart's measures of civic culture are primarily based on survey data that more directly reflect potential differences in mass civic orientations. ${ }^{14} \mathrm{We}$ first examine Inglehart's measures of political culture, and assess the linkages between these measures and other factors in order to evaluate their construct validity.

\section{Measuring Political Culture}

Following Almond and Verba (1963), Inglehart identifies the following seven specific indicators of mass political culture:

1. Levels of overall life satisfaction,

2. Levels of interpersonal trust,

3. Support for revolutionary change,

4. Support for the current social order,

5. Levels of political discussion,

6. Levels of postmaterialist values,

7. Proportion of the population Protestant.

Measures of the first six indicators of political culture are from Inglehart (1990, chap. 1), and refer to the early 1980s. Further details on these measures are provided in the Appendix. Data on the last indicator, percentage Protestant c. 1965, are from Taylor and Hudson (1972). ${ }^{15}$

We have already emphasized the consistent claim in cultural accounts that indicators like these form a coherent cluster. Thus, Inglehart describes the first five of these items as constituting "a syndrome of positive attitudes toward the world in which one lives $(1990,41)$. Similarly, postmaterialists are said to place special weight on quality of life issues and on the sense of community, both of which involve the altruism, cooperative spirit, and

\footnotetext{
${ }^{14}$ To be sure, Putnam $(1993,109-18)$ does briefly compare scattered survey data on levels of powerlessness, trust, and satisfaction with life with his measure of current civic community, but his analyses do not rely primarily on these opinion data.

${ }^{15}$ Given its distribution, the variable used in Table 4 is the natural logarithm of the percentage Protestant (plus 1).
} 
Table 4. Product-moment Correlations among Seven Components of Political Culture, circa 1980

\begin{tabular}{lrrrrrrr}
\hline \hline & 1. & 2. & 3. & 4. & 5. & 6. & 7. \\
\hline 1. Satisfaction & - & \multicolumn{1}{c}{22} & 18 & 18 & 21 & 20 & 24 \\
2. Trust & .55 & - & 18 & 18 & 19 & 18 & 22 \\
3. \% Revolutionary & -.57 & -.52 & - & 18 & 17 & 15 & 18 \\
4. \% Conservative & .36 & .43 & -.40 & - & 17 & 15 & 18 \\
5. \% Materialist & -.66 & -.43 & .41 & -.36 & - & 18 & 21 \\
6. \% Women discussing & .62 & .45 & -.45 & .55 & -.61 & - & 20 \\
7. \% Protestant & .76 & .61 & -.24 & .48 & -.68 & .76 & - \\
\hline
\end{tabular}

Sources: Data on the first six indicators are from Inglehart (1990, chap. 1); information on Protestantism is the natural logarithm of the percentage Protestant scores from Taylor and Hudson (1972).

Entries below the main diagonal are pair-wise correlation coefficients, and entries above the main diagonal indicate the number of cases for which those correlations are calculated.

general civic-mindedness typically associated with civic virtue. Finally, Protestantism is also described as part of this syndrome (1990, 50).

Is there evidence that these measures of political culture form an underlying coherent cluster of attitudes, as claimed by Inglehart? Table 4 displays the correlations among the seven indicators of political culture. Because some of these indicators are available for more countries than others, we report pair-wise correlation coefficients below the main diagonal, and indicate the number of cases over which the correlations are calculated above the main diagonal. ${ }^{16}$ Given the coding of the variables, the signs of the coefficients are all as expected. Yet the most striking feature of these correlations is their comparatively modest size, given that they are calculated for national aggregates. Ignoring signs, the 21 correlations in the table range from .24 to .76 , with a mean value of .52 . Only two (approximately $10 \%$ ) exceed .70, which translates into an $R^{2}$ of .50 . This means that only in these two pairings of indicators is more than half the variance shared. Across the remaining 19 pairings, the shared variances are considerably smaller. The modest size of most of the correlations in Table 4 challenges the assertion that these indicators are all components of a single enduring and distinctive cluster of cultural traits.

\footnotetext{
${ }^{16}$ Despite his claim that these variables form a coherent cluster, Inglehart does not himself report a correlation matrix (or factor analysis) that includes all the variables shown in Table 6. A factor analysis of these variables seems unwise in view of (a) the lack of structure in the correlations in Table 6 and (b) the variation across the items in the incidence of missing data that is evident above the main diagonal.
} 


\section{Sources of Political Culture}

An alternative way of gauging whether these indicators form a welldefined configuration is to see if they are generated by the same underlying economic conditions. Civic virtue should be more widespread within the wealthier democracies, all else equal, for the reasons advanced by Inglehart (among other things, national wealth takes time to accumulate and is therefore a long-term condition that changes comparatively slowly). By the same token, civic virtue should be less sensitive to shorter-term economic conditions (e.g., economic growth in the recent past) or economic conditions that are more prone to temporal fluctuation (e.g., levels of unemployment). The claim that the indicators form a coherent cultural cluster necessarily implies, moreover, that they should each respond in a similar manner to the same economic conditions.

Table 5 reports the estimates from regressions of the indicators of political culture on economic conditions. These estimates involve separate regressions of the first six components from Table 4 (all of which entail values measured in 1980 or very shortly thereafter), but exclude the measure of Protestantism, which is for c. 1965. The six elements are regressed on (a) national wealth, as indexed by the logarithm of real GDP per capita for 1980 , (b) economic growth over the previous decade, as measured by growth in real GDP per capita (1970-80), and (c) the level of unemployment for $1980 .{ }^{17}$ The cultural argument, of course, implies that the explanatory variables in Table 5 should have similar effects on each of the six component indicators.

From the first row of the table, we see that national differences in levels of life satisfaction are sensitive to the level of economic development and economic growth over the prior decade, but do not vary with levels of unemployment. Specifically, levels of satisfaction are higher in wealthier countries and in those that experienced lower growth rates over the previous 10 years. This pattern is repeated in the estimates for the percentage materialist. The sign reversals here merely reflect the coding of the dependent variable (percentage materialist minus percentage postmaterialist), so the coefficients in the fifth row show that postmaterialism increases with level of development and decreases with prior growth. In contrast, when we turn to levels of interpersonal trust in the second row of the table, only the coefficient for unemployment is statistically significant. Distrust seems to increase with unemployment, but is insensitive to either the level of development or growth in the recent past. A similar pattern is obtained with the percentage of women discussing politics in the bottom row of the table (the

${ }^{17}$ Data for levels and growth of real GDP are from Summers and Heston (1991); those for levels of unemployment are from OECD (1991). 
Table 5. Regressions of Components of Political Culture, circa 1980, on Basic Economic Conditions [Coefficients $(t$-ratios)]

\begin{tabular}{|c|c|c|c|c|c|c|}
\hline Dependent Variable & $\begin{array}{c}\text { Per } \\
\text { capita } \\
\text { GDP } \\
1980\end{array}$ & $\begin{array}{c}\text { GDP } \\
\text { growth } \\
1970-80\end{array}$ & Unemployment & Constant & $R^{2}$ & $N$ \\
\hline Satisfaction & $\begin{array}{l}1.19^{*} \\
(2.6)\end{array}$ & $\begin{array}{c}-2.96^{*} \\
(2.2)\end{array}$ & $\begin{array}{l}-.02 \\
(0.5)\end{array}$ & $\begin{array}{c}-2.76 \\
(0.6)\end{array}$ & .60 & 20 \\
\hline Trust & $\begin{array}{c}0.73 \\
(0.1)\end{array}$ & $\begin{array}{r}-28.91 \\
(1.1)\end{array}$ & $\begin{array}{c}-2.46^{*} \\
(2.6)\end{array}$ & $\begin{array}{c}56.65 \\
(0.7)\end{array}$ & .37 & 18 \\
\hline$\%$ Revolutionary & $\begin{array}{c}-3.93^{*} \\
(2.0)\end{array}$ & $\begin{array}{l}10.20 \\
(1.5)\end{array}$ & $\begin{array}{l}0.52^{*} \\
(2.2)\end{array}$ & $\begin{array}{c}35.94 \\
(1.8)\end{array}$ & .58 & 16 \\
\hline$\%$ Conservative & $\begin{array}{l}10.80 \\
(1.8)\end{array}$ & $\begin{array}{l}25.53 \\
(1.2)\end{array}$ & $\begin{array}{c}-1.84^{*} \\
(2.5)\end{array}$ & $\begin{array}{r}-71.53 \\
(1.2)\end{array}$ & .55 & 16 \\
\hline$\%$ Materialist & $\begin{array}{c}-19.16^{*} \\
(2.6)\end{array}$ & $\begin{array}{l}57.98^{*} \\
(2.6)\end{array}$ & $\begin{array}{c}0.29 \\
(0.4)\end{array}$ & $\begin{array}{c}181.33^{*} \\
(2.5)\end{array}$ & .64 & 19 \\
\hline$\%$ Women discussing & $\begin{array}{l}11.94 \\
(1.2)\end{array}$ & $\begin{array}{r}-41.41 \\
(1.2)\end{array}$ & $\begin{array}{c}-1.88 \\
(1.9)\end{array}$ & $\begin{array}{r}-30.42 \\
(0.3)\end{array}$ & .46 & 18 \\
\hline
\end{tabular}

Sources: For the dependent variables, see Table 1. GDP data are from Summers and Heston (1991) and unemployment data are from OECD (1991).

* Starred coefficients are more than twice their standard errors.

coefficient for which has a $t$-ratio of 1.9), suggesting that political interest declines with increasing unemployment. Finally, the two items on support for the existing social order behave in a parallel manner (reflecting in part the fact that they are based on different responses to the same question). Support for the current order is higher in wealthier countries and in those with lower unemployment, but does not vary with recent growth. ${ }^{18}$

Overall, the patterns apparent in Table 5 reinforce the inferences we drew from Table 4. The six "components" of political culture do not form a coherent general structure: instead, they are sensitive to different factors. Even the first three components in the table do not cluster together, despite Inglehart's use of these three as a summary measure of political culture in his Figure $1.6(1990,44)$. The similarities that are evident in Table 5 are not clearly interpretable, moreover: why, for example, should life satisfaction and materialism respond differently to economic conditions than do levels of trust and the percentage of women who discuss politics? Finally, insofar as growth in the recent past and levels of unemployment reflect

${ }^{18}$ The same patterns as those reported in Table 5 are obtained if the measure of economic growth is taken to cover an even shorter period (1975-80) that focuses on economic performance after the oil shock of 1974. 
shorter-term economic patterns, the fact that these two variables influence some but not all of the components is incompatible with the interpretation that the latter represent enduring cultural values. ${ }^{19}$

\section{Effects of Political Culture}

The question that remains is whether any or all of these cultural indicators influence other outcomes. Inglehart's claim that they do echoes the earlier suggestion (Almond and Verba 1963) that civic virtue is essential for a successful democracy, and anticipates Putnam's (1993) parallel linkage between civic virtue and effective governance. Inglehart goes on to suggest that civic virtue also impinges on economic growth. We briefly discuss these issues in turn.

Inglehart's conclusion that culture influences the success of democracy depends on two pieces of evidence. First, he reports a correlation of .85 between life satisfaction and democracy $(1990,42)$. Second, he claims that the effects of economic development on democracy are mediated by the proportion of the labor force in the tertiary sector and by "civic culture" (as reflected in levels of life satisfaction and interpersonal trust, and support for revolutionary change). The meaning one attaches to these associations hinges decisively, however, on how one identifies "successful democracies."

The particular measure used by Inglehart is a count of the years of continuous democracy from 1900 through 1986. The measure and the research design within which it is employed, however, contain several anomalies. First, as one would correctly expect given the title of his book, the countries analyzed by Inglehart consist almost exclusively of the advanced industrial societies (the notable exceptions in his Figure 1.5 are Argentina, Hungary, and South Africa [Inglehart 1990, 42]). Their levels of democratic performance as of the early to middle 1980 s were, as a result, all roughly equivalent (see Bollen 1993). Under this procedure, however, Belgium,

\footnotetext{
${ }^{19}$ Clarke and Dutt (1991) found a similar problem. The results from their pooled crosssectional time series analysis of eight countries over the period 1976-86 indicate "that sharp increases in unemployment in the early 1980s make it appear, based on the four-item measure, that there was a substantial shift toward postmaterialism in several countries." They conclude that the upward trend stemmed more from "the failure to include an unemployment statement in the measure" than from changes in underlying values $(1991,918)$. In another pooled analysis of some of these items from eight countries, Clarke, Dutt, and Kornberg (1993) provide further evidence of the sensitivity of these items to short-run economic and political circumstances including inflation, unemployment, fluctuations in support for political parties, and rally-around-the-flag events. Duch and Taylor (1993) reach the parallel conclusion that apparent shifts in postmaterialism stem disproportionately from the inclusion of an inflation item in the index. All of these analyses underscore the sensitivity of Inglehart's measures to short-run rather than long-term economic conditions.
} 
which is coded as continuously democratic since 1900 , is measured as being three times more democratic than France, whose democratic history is coded as beginning in 1958. The judgment that Belgium really was approximately three times more democratic than France by 1980 is untenable, given any reasonable set of criteria for democratic performance.

Second, Inglehart's use of 1900 as the starting date ignores the fact that the meaning of democracy has evolved considerably over this century, especially in terms of what Dahl (1971) has labelled inclusiveness. When one recalls the typical restrictions on the suffrage based on gender, income, and race 90 years ago, the implications of this evolution become self-evident: since 1900, none of the countries so coded by Inglehart has been continuously democratic in a contemporary sense. This problem undermines all attempts to identify a binary starting date after which a country can be considered democratic and before which it cannot.

Third, Inglehart's analysis does not help account for levels of democratic performance because his research design selects cases according to their (high) values on that dependent variable (see Geddes 1990). Variations in political culture (or any other potential explanatory variable) cannot logically be used to account for fundamentally uniform degrees of political democracy. That Inglehart's measure includes more variance does not obviate the problem. It simply means that his measure inadvertently conflates democracy with at least one other variable - political stability (Bollen and Jackman 1989). ${ }^{20}$

Given the above, the associations reported by Inglehart should most plausibly be taken to reflect covariation between culture and stability, not between culture and democratic performance. They therefore do not address the issues that have motivated scholars, at least since Almond and Verba, concerning the impact of democratic (i.e., civic) values on democratic performance. Further, these associations cannot logically sustain the causal argument at stake, because that argument implies that the distribution of values identified in surveys administered in the early 1980s gave rise to the stability of constitutional orders over the preceding 85 years.

${ }^{20}$ Duch and Taylor point to a related problem: "recent survey evidence from the Soviet Union and Eastern and Central Europe suggests the mass public embraces postmaterialist values in spite of the serious economic penury they have endured" $(1993,753)$. Inglehart explains this apparent anomaly as follows: "the crucial factor is security during one's formative years, and it is clear that the communist regimes of Eastern Europe provided a relatively secure existence ..." (Inglehart 1992, 14, quoted in Duch and Taylor 1993, 753). In making this argument Inglehart confounds economic security and economic development. The result is an unfalsifiable argument: "economic security drives postmaterialism, but if we see high levels of postmaterialism and low economic development at the same time, then factors other than economic wealth have promoted economic security" (Duch and Taylor 1993, 753). 
If the claim for an effect on democracy is weak, so too is the assertion that civic virtue influences economic growth. To be sure, Inglehart does label his discussion as "speculation with data" $(1990,40)$. On the other hand, his appraisal concludes with the following:

Economic development itself is influenced by cultural variables. ... The available evidence supports Weber's insight that culture is not just a consequence of economics; it can shape the basic nature of economic and political life (Inglehart 1990, 65).

As evidence, Inglehart compares the modest correlation between the level of economic development and economic growth rates $(r=-.22)$, with the "far stronger" relationship between postmaterialism and economic growth during the period 1965-84 ( $r=-.54)$. Thus, while a nation's wealth can affect the rate at which its economy grows, Inglehart maintains that it does so ". . . only insofar as it brings cultural change" $(1990,64)$. In this vein,

Evidence from a cross-national perspective converges with evidence from the individual level, pointing to a long-term cultural process of negative feedback linked with economic growth. . . . The wealthier societies are least likely to produce Materialist publics, but Materialist publics seem to produce high economic growth rates. . . . Since one's values tend to reflect the conditions prevailing during one's preadult years, we allow a lag of about thirty years between [level of economic development and mass value priorities]. . . (Inglehart 1990, 57).

To substantiate these claims, Inglehart reports a correlation of $r=-.59$ between a nation's per capita GNP in 1950 and the percentage of the national population holding Materialist values, c. $1980(1990,57) \cdot{ }^{21}$ This argument implies that the configuration of mass value priorities prevailing in the early 1980 s should be systematically related to economic growth rates in the following period. We therefore estimate separate regressions of 1980-88 RGDP per capita growth rates on each of Inglehart's measures of cultural values for c. 1980, controlling for 1980 RGDP per capita (see Table 6).

The analysis in Table 6 indicates that the relationship between culture and economic growth rates is weak to nonexistent. Out of seven separate regressions, not one coefficient estimate for mass value priorities is statistically significant. On the other hand, the estimate for the level of national

\footnotetext{
${ }^{21}$ Inglehart's discussion of changes in the signs of the coefficients on economic growth that occur when different periods are investigated is somewhat puzzling. The issues at stake here are part of an ongoing controversy about whether industrial economies are converging (e.g., De Long 1988; Baumol and Wolf 1988; and Maddison 1991).
} 
Table 6. Regressions of Current Growth Rates (1980-88) on Different Cultural Values Controlling for 1980 GDP [coefficients ( $t$-ratios)]

\begin{tabular}{lccccc}
\hline \hline Measure of & Culture & Per capita & & & \\
Political Culture & c. 1980 & GDP 1980 & Constant & $R^{2}$ & $N$ \\
\hline Satisfaction & -0.04 & $0.19^{*}$ & $-1.31^{*}$ & .42 & 24 \\
& $(1.3)$ & $(3.6)$ & $(3.5)$ & & \\
Trust & 0.00 & $0.12^{*}$ & $-1.07^{*}$ & .45 & 22 \\
& $(1.5)$ & $(2.7)$ & $(2.8)$ & & \\
\% Revolutionary & -0.01 & 0.06 & -0.39 & .38 & 18 \\
& $(1.3)$ & $(1.0)$ & $(0.7)$ & & \\
\% Conservative & 0.00 & $0.11^{*}$ & $-0.91^{*}$ & .31 & 18 \\
& $(0.2)$ & $(2.3)$ & $(2.1)$ & & \\
\% Materialist & 0.00 & $0.15^{*}$ & $-1.28^{*}$ & .35 & 21 \\
& $(1.5)$ & $(3.0)$ & $(2.7)$ & & \\
\% Women discussing & -0.00 & 0.06 & -0.43 & .12 & 20 \\
& $(0.4)$ & $(1.5)$ & $(1.1)$ & & \\
\% Protestant & -0.00 & $0.15^{*}$ & $-1.21^{*}$ & .37 & 24 \\
& $(0.4)$ & $(3.3)$ & $(3.0)$ & & \\
\hline
\end{tabular}

Sources: see Tables 6 and 7.

* Starred coefficients are more than twice their standard errors.

wealth is in the expected direction in all cases, and significant in all but two of the analyses. ${ }^{22}$ In sum, there is no systematic relationship between any indicator of culture and current economic growth rates.

Taken together, the estimates presented in Tables 4 through 6 offer scant support for the arguments advanced by Inglehart. First, our analyses challenge his arguments regarding the existence of an enduring and distinctive cluster of cultural traits. Second, we find that Inglehart's measures of culture are sensitive to short-term fluctuations in economic growth rates and the level of unemployment. This sensitivity varies by indicator, moreover: levels of life satisfaction and postmaterialism are systematically affected by economic growth rates, but are relatively insensitive to levels of

${ }^{22}$ To duplicate Inglehart's procedure more closely, we also performed bivariate regressions between his measures of culture and current economic growth rates. Out of seven regressions, we initially found two significant relationships. The estimates for Trust and percent Revolutionary were both statistically significant $(p<.02)$. Inspection of the leverage plots revealed, however, that both relationships were dependent upon the distorting effects of influential points (Bollen and Jackman 1990). In the former, the values for South Africa and Argentina drove the relationship; while in the latter, the measure for South Africa was responsible for the distortion. With these cases removed, the $p$ values increased to .30 and 42 , respectively. 
unemployment. On the other hand, the opposite pattern obtains for levels of trust and the percentage of women who discuss politics. Finally, our analyses challenge the claim that "culture" has any systematic effects on either political democracy or economic growth.

\section{Conclusions}

Our purpose has been to evaluate the general claims advanced in the two leading recent studies of political culture. Central to those analyses is the idea that political cultures stem from distinctive and coherent configurations of attitudes across broad groups of citizens. The available survey data reported by Inglehart (1990), however, do not warrant this conclusion. The correlations among the aggregate indicators of mass value priorities are relatively modest in size (on average, about .50), and therefore cannot be used as evidence of a coherent configuration of mass value priorities. Putnam's analyses (1993) do not directly address this issue: while the statistical evidence indicates that his indicators of civic culture can be used to generate a unidimensional measure, the meaning of the resulting measure is unclear, and this problem is compounded by the fact that the measure does not focus directly on clusters of attitudes.

Second, we have found no evidence for durable cultural syndromes. This durability of culture is pivotal to both Putnam's and Inglehart's claims: cultural norms persist over the long term (measured occasionally in centuries by Putnam), and are only slightly modified in the short term. We provide evidence that Inglehart's measures of political culture are influenced significantly by short-term factors (unemployment and economic growth). We find, moreover, that the degree of sensitivity to these short-term factors varies by indicator, with life satisfaction and postmaterialism significantly affected by economic growth over the previous decade, but relatively insensitive to levels of unemployment, and the opposite pattern occurring for the measures of trust and revolutionary sentiments. Putnam's data do not allow us to gauge the durability of cultural norms, because they do not reflect attitudinal configurations.

Finally, we have found no evidence to suggest that cultural factors have any systematic effects on political and economic outcomes. In the Italian case, there are strong correlations between the overall measures of culture and "institutional performance" discussed by Putnam (1993). Our reexamination of the data suggests, however, that these are an artifact of Putnam's particular application of principal components analysis, not a reflection of any underlying causal relationship. Indeed, we find no evidence to suggest that the indicators examined by Putnam can be meaningfully combined into an overall measure of political performance. Separate regression analyses employing the individual component indicators of institutional performance 
reveal that the vast majority of the coefficients are indistinguishable from zero, using conventional statistical criteria.

Turning to differences across the industrial democracies, we find no systematic linkage between any of Inglehart's measures of culture and subsequent economic growth. Although a correlation does exist between the years of democratic experience and the configuration of mass value priorities, this association conflates democracy with stability. Inglehart's analysis suffers from selection bias, moreover, since almost all of the countries in his sample are highly democratic. These problems undermine any attempts to draw the causal inferences implied by the cultural account from the observed correlations between "culture" and "democracy."

Would different research designs obviate some of these empirical difficulties and generate more convincing support for a cultural approach? We think not, on two counts. First, Putnam's and Inglehart's studies are easily the most extensive empirical statements on behalf of political culture in recent years, and they are accounts that have received considerable acclaim. Besides, the results we have reported in this paper parallel the failure of other studies to link culture with rates of mass political participation (e.g., Powell 1986; Jackman 1987; Jackman and Miller 1995), a pattern of particular significance given that earlier studies of political culture (e.g., Almond and Verba 1963) were primarily concerned with advancing our knowledge of mass political behavior. We thus conclude that the general explanatory value of political culture is, at best, limited.

Second, following Hirschman (1984), we have underscored the theoretical continuities linking the earlier studies with current studies of political culture, and noted the Weberian origins of both. The original studies of political culture, of course, drew heavily on anthropological analyses of culture of the 1950s and 1960s. It is important to understand, however, that the latter have more recently come under increasing criticism by anthropologists for empirical inaccuracies, excessive cultural determinism, a romantic cultural relativism, and a fundamental tendency toward post hoc explanation (e.g., Spiro 1987, esp. chaps. 1, 2; Brown 1991; Billig 1994).

Given the above, further attempts to refine and test the case for political culture along the lines we have addressed seem unlikely to be productive. We believe it may prove fruitful to recast the puzzle in more institutional terms, and in the process to endogenize political culture (again, adopting Hirschman's suggestion) ${ }^{23}$ We have already noted that institutional varia-

\footnotetext{
${ }^{23}$ In this vein, an important recent analysis of the Sicilian Mafia identifies the weaknesses of the common subcultural explanation of the phenomenon summarized by Putnam (1993, 146-8) and argues instead that distrust is endogenous, a characteristic that is perpetuated and expanded by organized crime (Gambetta 1993). Trust, of course, is central to Putnam's and Inglehart's treatment of civic virtue.
} 
tions provide a parsimonious and powerful explanation of political participation rates across the industrial democracies. Such an argument, of course, is not restricted to voter turnout rates, but can be elaborated to help account for political performance more generally.

Distinctive to this approach are the propositions that institutions-political, social, and economic-structure the distribution of incentives for individual action, and that individuals optimize in view of those constraints (Riker 1990, 172). ${ }^{24}$ Institutional change alters the opportunities available to political actors, and, even allowing for some stickiness, thereby modifies the behavior of those actors. In contrast to the cultural argument, which essentially takes incentive structures as given, this perspective directs our attention to the opportunity structures within which key political figures make strategic choices (e.g., Geddes 1994; Strom, Budge, and Laver 1994; Jackman and Volpert 1996), and thus restores political considerations to a central analytic role.

It could perhaps be countered that differences in institutional forms themselves simply reflect cultural variations. The problem then is that institutions are divorced from their political origins. We think it more profitable to cast institutions as the result of conflict over the allocation of valued goods. Phrased differently, institutions reflect " . . . the efforts of some to constrain the actions of others with whom they interact" (Knight 1992, 19). Institutions by this reckoning do not reveal cultural differences but are instead products of interdependent strategies of groups to achieve distributional gains (Shepsle 1989). As Knight points out, moreover, " to the extent that such rules can have substantive effects on social outcomes, the substantive content of those rules should reflect the self-interest that motivates these claims and actions" (1992, 38). Institutions thus acquire stability when groups with the resources to alter the rules of the game accept those rules; institutional change occurs when group(s) with sufficient power are able to challenge and transform those rules. In this way, institutions condition the distribution of both political and social resources.

Manuscript submitted 3 February 1995.

Final manuscript received 24 August 1995.

\footnotetext{
${ }^{24}$ Occasionally, cultural values are cast in similar terms. For example, Greif treats them as the beliefs "that capture individual's expectations with respect to actions that others will take in various contingencies"' $(1994,915)$. Note that this usage diverges substantially from that common in discussions of political culture, and deals with cultural values as a component of institutional arrangements.
} 


\section{APPENDIX Inglehart's Indicators of Political Culture}

1. Feelings of overall life satisfaction are generated from the following question:

Generally speaking, how satisfied are your with your life as a whole? Would you say that you are very satisfied, fairly satisfied, not very satisfied, or not at all satisfied? (Inglehart 1990, 25-6).

The national level of satisfaction is revealed by the proportion reporting "very satisfied" in the sample. As Inglehart observes, this is a very diffuse attitude that does not reflect political or economic performance of the moment, so that crossnational differences in this orientation are "remarkably enduring" $(1990,25)$.

2. Levels of "interpersonal trust" are identified from the following item:

Now I would like to ask you about how much you would trust people from various countries. For each country, please say whether, in your opinion, they are generally very trustworthy, fairly trustworthy, not particularly trustworthy, or not at all trustworthy (Inglehart 1990, 34).

Levels of trust are measured by the percentage in each country identifying most people of their "own nationality" as very or fairly trustworthy.

3. and 4. Evaluations of the current social order are manifested in responses to the following item:

[SHOW CARD] On this card are three basic kinds of attitudes concerning the kind of society we live in. Please choose the one that best describes your own opinion:

1. The entire way our society is organized must be radically changed by revolutionary action.

2. Our society must be gradually improved by reforms.

3. Our present society must be valiantly defended against all subversive forces.

Inglehart's third and fourth indicators of political culture (percent revolutionary and conservative, respectively) come from responses to options 1 and 3 on this item.

5. Levels of political discussion are tapped by the following question:

When you get together with your friends, would you say that you discuss political matters frequently, occasionally, or never?

For the reasons advanced by Inglehart $(1990,50-2)$, we restrict our attention to the percentage of women reporting that they discuss politics either frequently or occasionally.

6. Materialist/postmaterialist values are inferred from items asking people to rank the following goals (Inglehart 1990, 74-5):

A. Maintain order in the nation 
B. Give people more say in the government

C. Fight rising prices

D. Protect freedom of speech

E. Maintain a high rate of economic growth

F. Make sure that this country has strong defense forces

G. Give people more say in how things are decided at work and in their community

H. Try to make our cities and countryside more beautiful

I. Maintain a stable economy

J. Fight against crime

K. Move toward a friendlier, less impersonal society

L. Move toward a society where ideas count more than money

(In some of his analyses Inglehart has relied on the first four items while on other occasions he has employed all 12. It is not clear which set is used in Inglehart [1988 or 1990, chap. 1]. Either way, note that items such as B, D, and G specifically emphasize democratic values. Note further the discussion of the meaning of these items by Clarke and Dutt [1991], and by Duch and Taylor [1993].)

Postmaterialist values are said to stem from a decreasing emphasis on economic and physcial security accompanied by an increasing emphasis on nonmaterial needs, "such as a sense of community and the quality of life"' (Inglehart 1990, 56). Following Inglehart, we focus on the percentage of the population expressing materialist values minus the percentage expressing nonmaterialist values.

\section{REFERENCES}

Aldrich, John H. 1993. "Rational Choice and Turnout." American Journal of Political Science 37:246-78.

Almond, Gabriel A., and Sidney Verba. 1963. The Civic Culture. Princeton: Princeton University Press.

Almond, Gabriel A., and Sidney Verba. 1980. The Civic Culture Revisited. Boston: Little, Brown.

Armstrong, J. Scott. 1967. "Derivation of Theory by Means of Factor Analysis or Tom Swift and his Electric Factor Analysis Machine." American Statistician 21:17-21.

Banfield, Edward C. 1958. The Moral Basis of a Backward Society. New York: Free Press.

Barry, Brian. 1970. Sociologists, Economists and Democracy. Chicago: University of Chicago Press.

Baumol, William J., and Edward N. Wolf. 1988. "Productivity Growth, Convergence, and Welfare." American Economic Review 78:1155-63.

Billig, Michael S. 1994. "The Death and Rebirth of Entrepreneurism on Negros Island, Philippines: A Critique of Cultural Theories of Enterprise." Journal of Economic Issues 28:659-78.

Bollen, Kenneth A. 1993. "Liberal Democracy: Validity and Method Factors in Crossnational Measures." American Journal of Political Science 37:1207-30.

Bollen, Kenneth A., and Robert W. Jackman. 1989. "Democracy, Stability, and Dichotomies.” American Sociological Review 54:605-14. 
Bollen, Kenneth A., and Robert W. Jackman. 1990. “'Regression Diagnostics: An Expository Treatment of Outliers and Influential Cases." In Modern Methods of Data Analysis, ed. John Fox and J. Scott Long. Newbury Park, CA: Sage.

Brown, Donald E. 1991. Human Universals. New York: McGraw-Hill.

Butler, David, and Austin Ranney. 1994. Referendums Around the World: The Growing Use of Direct Democracy. Washington, DC: American Enterprise Institute.

Clarke, Harold D., and Nitish Dutt. 1991. "Measuring Value Change in Western Industrialized Societies: The Impact of Unemployment." American Political Science Review 85: 905-20.

Clarke, Harold D., Nitish Dutt, and Allan Kornberg. 1993. "The Political Economy of Attitudes Toward Polity and Society in Western European Democracies." Journal of Politics 55:998-1021.

Dahl, Robert A. 1971. Polyarchy: Participation and Opposition. New Haven: Yale University Press.

De Long, J. Bradford. 1988. “Productivity Growth, Convergence, and Welfare: Comment." American Economic Review 78:1138-54.

Duch, Raymond M., and Michaell A. Taylor. 1993. "Postmaterialism and the Economic Condition." American Journal of Political Science 37:747-79.

Dunteman, George H. 1989. Principal Components Analysis. Newbury Park, CA: Sage.

The Economist. 1993. "Pro Bono Publico.” February 6:96.

Flury, Bernhard. 1988. Common Principal Components and Related Multivariate Methods. New York: Wiley-Interscience.

Gambetta, Diego. 1993. The Sicilian Mafia: The Business of Private Protection. Cambridge: Harvard University Press.

Geddes, Barbara. 1990. "How the Cases You Choose Affect the Answers You Get: Selection Bias in Comparative Politics." Political Analysis 2:131-50.

Geddes, Barbara. 1994. Politician's Dilemma: Building State Capacity in Latin America. Berkeley and Los Angeles: University of California Press.

Greif, Avner. 1994. "Cultural Beliefs and the Organization of Society: A Historical and Theoretical Reflection on Collectivist and Individualist Societies." Journal of Political Economy 102:912-50.

Hirschman, Albert O. 1984. “A Dissenter's Confession: 'The Strategy of Economic Development' Revisited." In Pioneers in Development, ed. Gerald M. Meier and Dudley Seers. New York: Oxford University Press.

Inglehart, Ronald. 1988. "The Renaissance of Political Culture." American Political Science Review 82:1203-30.

Inglehart, Ronald. 1990. Culture Shift in Advanced Industrial Society. Princeton: Princeton University Press.

Jackman, Robert W. 1987. "Political Institutions and Voter Turnout in the Industrial Democracies." American Political Science Review 81:405-23.

Jackman, Robert W. 1993. "Rationality and Political Participation." American Journal of Political Science 37:279-90.

Jackman, Robert W., and Ross A. Miller. 1995. "Voter Turnout in the Industrial Democracies During the 1980s." Comparative Political Studies 27:467-92.

Jackman, Robert W., and Karin Volpert. 1996. "Conditions Favoring Parties of the Extreme Right in Western Europe." British Journal of Political Science 26: in press.

Kim, Jae-On, and Charles W. Mueller. 1978. Factor Analysis: Statistical Methods and Practical Issues. Newberry Park, CA: Sage.

Knight, Jack. 1992. Institutions and Social Conflict. New York: Cambridge University Press. 
Laitin, David D. 1995. “The Civic Culture at 30." American Political Science Review 89: 168-73.

Maddison, Angus. 1991. Dynamic Forces in Capitalist Development: A Long-Run Comparative View. New York: Oxford University Press.

Manchester, William. 1993. A World Lit Only by Fire. Boston: Little, Brown.

McClelland, David C. 1961. The Achieving Society. Princeton: D. Van Nostrand Co.

McClelland, David C. 1963. "National Character and Economic Growth in Turkey and Iran." In Communications and Political Development, ed. Lucian W. Pye. Princeton: Princeton University Press.

Moore, Barrington. 1966. Social Origins of Dictatorship and Democracy. Boston: Beacon Press.

Organization for Economic Cooperation and Development. (OECD). 1991. OECD Economic Outlet: Historical Statistics. Paris: Organization for Economic Cooperation and Development.

Portes, Alejandro. 1976. "'On the Sociology of National Development: Theories and Issues." American Journal of Sociology 82:55-85.

Poundstone, William. 1993. Prisoner's Dilemma. New York: Anchor Books.

Powell, G. Bingham, Jr. 1986. "American Voter Turnout in Comparative Perspective." American Political Science Review. 80:17-43.

Putnam, Robert D. 1993. Making Democracy Work: Civic Traditions in Modern Italy. Princeton: Princeton University Press.

Putnam, Robert D. 1995. “Bowling Alone: America's Declining Social Capital.” Journal of Democracy 6:65-78.

Putnam, Robert D., Robert Leonardi, Raffaella Nanetti, and Franco Pavoncello. 1983. "Explaining Institutional Success: The Case of Italian Regional Government." American Political Science Review. 77:55-74.

Riker, William H. 1990. “Political Science and Rational Choice.' In Perspectives on Positive Political Theory, ed. James E. Alt and Kenneth A. Shepsle. New York: Cambridge University Press.

Shepsle, Kenneth A. 1989. "Studying Institutions: Some Lessons from the Rational Choice Approach." Journal of Theoretical Politics 1:131-47.

Spiro, Melford E. 1987. Culture and Human Nature. Chicago: University of Chicago Press.

Strom, Kaare, Ian Budge, and Michael J. Laver. 1994. "Constraints on Cabinet Formation in Parliamentary Democracies." American Journal of Political Science 38:303-35.

Summers, Robert, and Alan Heston. 1991. "The Penn World Table (Mark 5): An Expanded Set of International Comparisons.” Quarterly Journal of Economics 106:327-68.

Taylor, Charles L., and Michael C. Hudson. 1972. World Handbook of Political and Social Indicators. 2nd ed. New Haven: Yale University Press.

Valentine, Charles A. 1968. Culture and Poverty: Critique and Counter-Proposals. Chicago: University of Chicago Press.

Verba, Sidney. 1965. "Conclusion: Comparative Political Culture." In Political Culture and Political Development, ed. Lucian W. Pye and Sidney Verba. Princeton: Princeton University Press.

Weber, Max. [1905] 1958. The Protestant Ethic and the Spirit of Capitalism. Reprint. New York: Scribner's.

Zeitlin, Irving. 1990. Ideology and the Development of Modern Sociological Theory. 4th ed. Englewood Cliffs, NJ: Prentice-Hall.

Zeller, Richard A., and Edward C. Carmines. 1980. Measurement in the Social Sciences: The Link Between Theory and Data. New York: Cambridge University Press. 